\title{
Scrotal cancer in the West Midlands 1936-76
}

\author{
H A WALDRON, ${ }^{1}$ J A H WATERHOUSE, ${ }^{2}$ AND N TESSEMA ${ }^{1}$ \\ From the TUC Centenary Institute of Occupational Health, ${ }^{1}$ London School of Hygiene and Tropical \\ Medicine, London, and Birmingham and West Midlands Cancer Registery, ${ }^{2}$ Queen Elizabeth Medical Centre, \\ Birmingham, $U K$
}

ABSTRACT Between 1936 and 1976, 344 cases of scrotal cancer were registered in the West Midlands Region. There was a considerable increase in the number of registrations after 1955 , the figures remaining high until the 1970 s since when they appear to be falling towards the low level seen in the early years of registration. By the end of December 1981250 deaths had occurred. The cause of death was known in 226 cases and of these, $97(42 \cdot 9 \%)$ were attributed to cancer of the scrotum, $40(17.7 \%)$ to other malignancies, and $89(39.4 \%)$ to other causes, scrotal cancer not being mentioned on the death certificate. The mean age at registration was 59.3 years and at death 66 years. Mean survival was 6.6 years with a five year survival rate of $51 \%$. Survival was shorter in men who presented with palpable lymph nodes and greater in those treated with surgery alone. Occupations were known for all but 28 of the cases and of these, $61.9 \%$ had been exposed to mineral oil and a further $7.8 \%$ to pitch and tar. Among the occupations with exposure to mineral oil, tool setters and tool fitters accounted for the greatest proportion, 89 men having followed those trades. In 74 cases second primary tumours were registered after the scrotal primary, mostly in the skin and bronchus. There was no relation between the development of second primary tumours and exposure to mineral oil or to pitch and tar.

- Scrotal cancer was the first malignant disease to be shown to have a clear relationship with a particular occupation when Percivall Pott described its occurrence in chimney sweeps in 1775 . Since then, the disease has appeared successively in different occupational groups including workers exposed to pitch and tar, to shale oil, and to mineral oil. Tumours induced by mineral oil were especially prevalent in the 1920 s and 1930s in the cotton industry in Lancashire. Of those exposed, mule spinners were the most likely to contract the disease as their work of piecing together the broken threads on the mule caused them to lean over a faller bar which was covered with oil thrown off from the rapidly rotating spindles (fig 1). The faller bar was at groin height and the mule spinner's clothing became soaked with oil which thus came into contact with his scrotum. With the use of less carcinogenic oils in the cotton industry and with the decline of the industry itself, the incidence of scrotal cancer has fallen greatly in the north west of England' only to appear elsewhere.

In 1950 Cruickshank and Squire in Birmingham

Received 21 December 1982

Accepted 3 March 1983 reported some cases of epithelioma in men working in the engineering industry who had been in contact with the cooling oils used on certain automatic machines. ${ }^{2}$ Among their group of 34 patients with scrotal cancer, 12 had positive exposure to mineral oil, six having worked as machine operators. Given the long latent period of the disease and the relatively recent increase in the use of automatic machines, Cruickshank and Squire predicted that the incidence of the disease would probably increase. Their prediction appeared to be borne out by the increase in the number of cases of epitheliomatous ulceration reported to the factory inspectorate in the 1960 s, especially in the wake of the test case of Stokes $v$ Guest, Keen and Nettlefolds, in which the widow of a man who had contracted the disease successfully prosecuted her husband's employers for compensation. ${ }^{3}$

It was against this background that the present study was undertaken. The aims were to identify all the cases of scrotal cancer registered in the West Midlands Region* from 1936 to 1976, to establish

*The West Midlands Region comprises the counties of West Midlands, Warwickshire, Worcestershire and Hereford, Staffordshire, and Salop. 


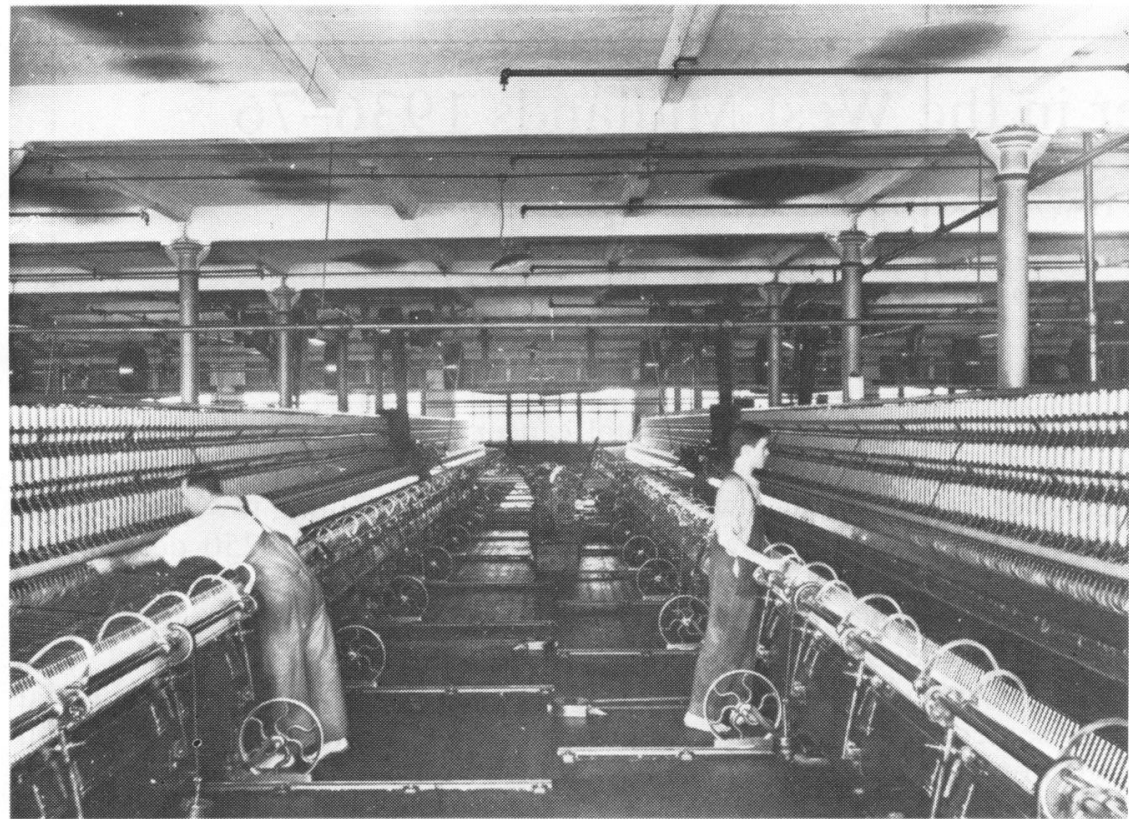

Fig 1 Cotton mule spinning showing the minder (left) leaning over the faller bar to piece together a broken thread. The assistant on the right was known as the young piecer.

the occupations of the men with the disease and their exposure to any known carcinogens, and, finally, to describe the course of the disease.

\section{Materials and methods}

Cases were drawn from the Regional Cancer Registry for the years 1936 to 1976 inclusive, these being the years when registration first began and the last date which would allow for a five year follow up (at least) on all cases. Information was taken from the registry records, supplemented where necessary from hospital case notes and from interviews with the patients or their relatives. Details of the presenting symptoms and of treatment were taken from the case notes; the cause of death was obtained from copies of the death certificates in the records. In order to measure duration of survival we determined whether patients were alive or dead on 31 December 1981, thus allowing for a minimum of five years follow up in each case. To establish trends with time, some of the data have been analysed for three successive periods, 1936-55, 1956-65, and 1966-76.

\section{Results}

\section{NUMBER OF CASES}

Between 1936 and 1976, 344 cases were registered but, as may be seen from fig 2 , the number of regis-

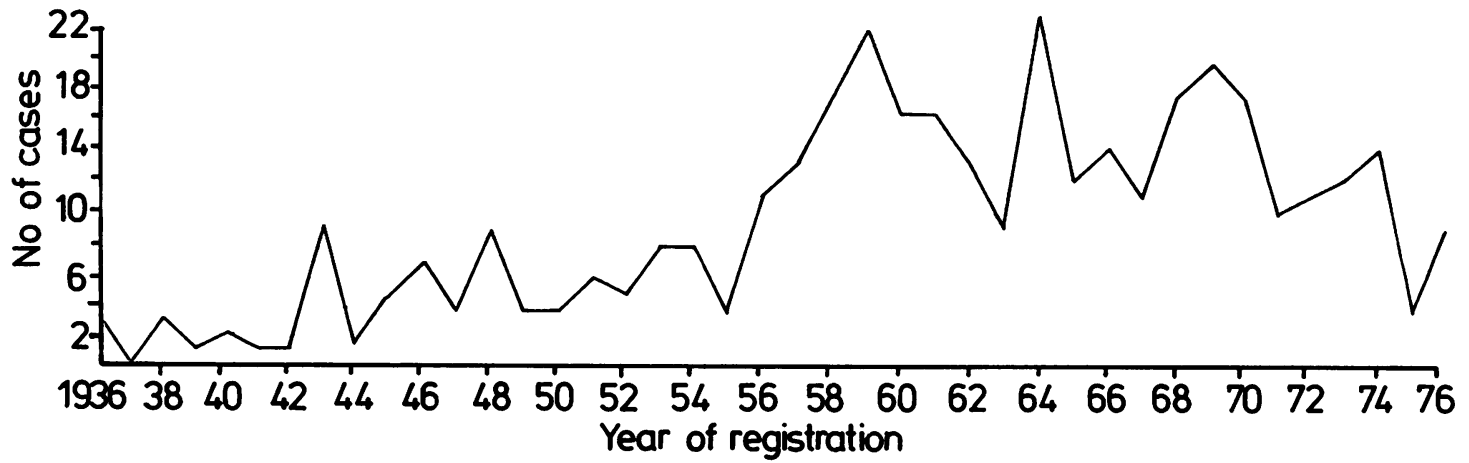

Fig 2 Annual number of registrations of cases with scrotal cancer. 
trations a year has not been constant. The number of registrations increased considerably after 1955 and the numbers have remained high, although there are fluctuations which appear to peak about every five or six years. There is some indication from fig 2 that the number of cases which fell in the 1970s may be returning towards the low levels seen in the early years of registration.

\section{NUMBER OF DEATHS AND CAUSE OF DEATH}

By the end of December 1981, 250 cases had died; the annual distribution of deaths (fig 3) shows a trend similar to that shown in fig 2. The cause of death was known for 226 cases and of these, 97 $(42.9 \%)$ were attributed to scrotal cancer, 40 $(17.7 \%)$ to other malignancies, and $89(39.4 \%)$ to other causes, scrotal cancer not being mentioned on the death certificates.

\section{AGE AT REGISTRATION AND AGE AT DEATH}

The mean age at registration was 59.3 years (range 22 to 88 ); the mean age at death was 66.0 (range 23 to 95) (fig 4). These ages have shown no tendency to change over time but, as may be seen from fig 4 , there is a deficit of cases aged between 60 and 64 . This deficit was thought to be almost certainly an artefact of registration and if so then it should disappear if the age at onset of the tumour was plotted. Age of onset was known with a reasonable degree of certainty for 92 cases, and in fig 5 the distribution by age of onset has been plotted and compared with age at registration for the same cases. The curve for age at onset shows no deficit but there is still a dip in the curve of age at registration in the 60-64 year group, although smaller than that for the group as a whole (fig 4).

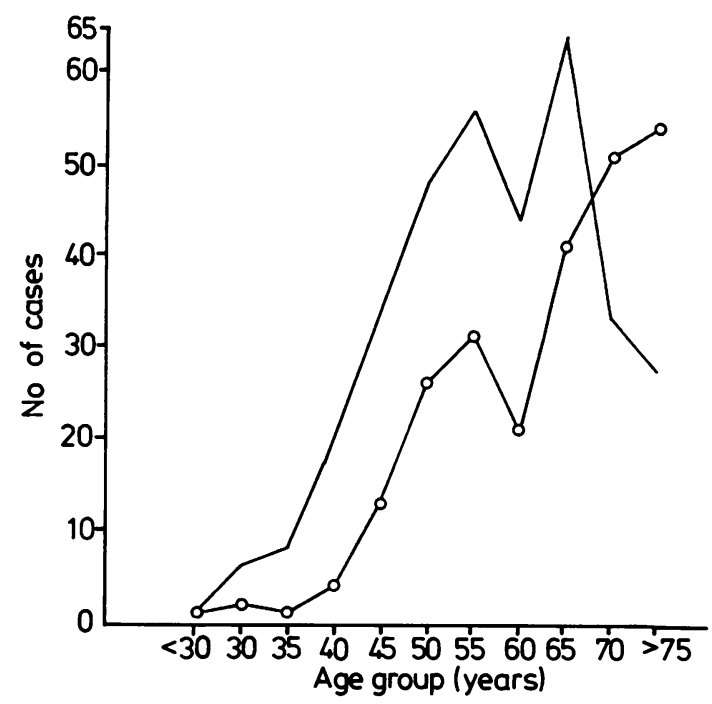

Fig 4 Mean age at registration (open circles) and death (solid line) of cases of scrotal cancer.

\section{OCCUPATIONS}

The occupations of all but 28 of the cases were known and the principal of these are shown in table 1. Men with exposure to mineral oil account for $61.9 \%$ of the total and a further $7.8 \%$ had exposure to pitch and tar. Among the occupations with oil exposure, tool setters and tool fitters account for the greatest proportion. The earliest record of a man with scrotal cancer in a job with oil exposure was in 1936; the first tool setter was registered in 1940.

Six men had been cotton spinners, their exposure having taken place outside the region, and there were seven sweeps; in 57 cases $(16.6 \%)$ there was

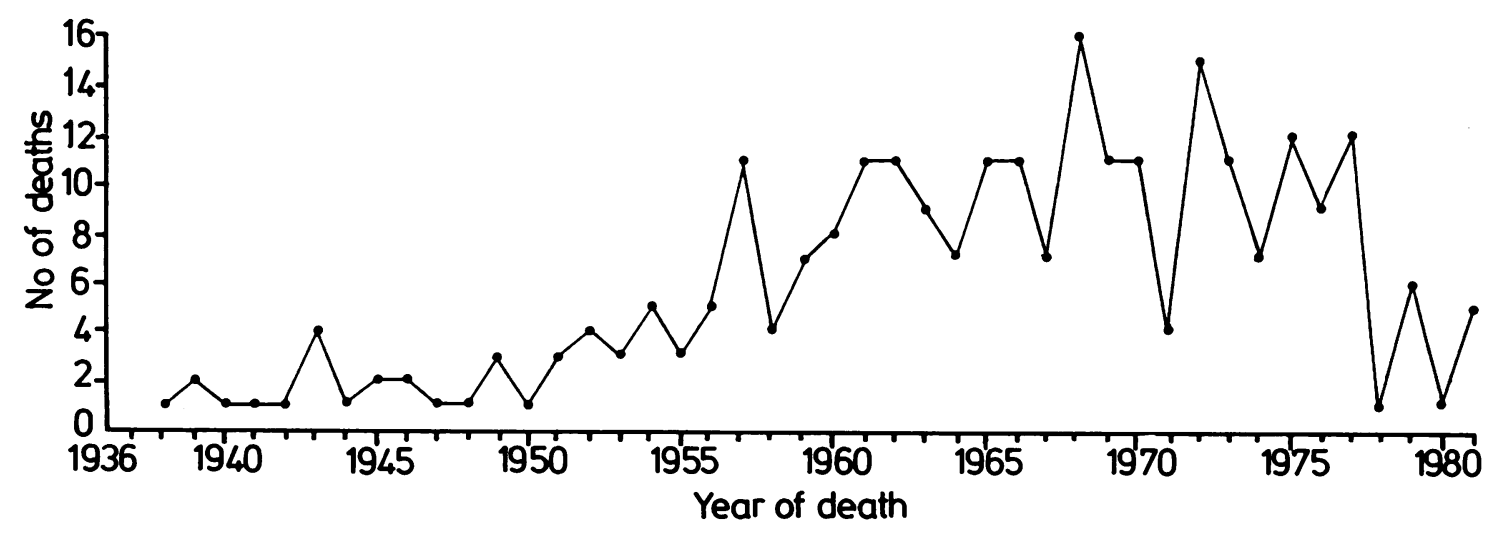

Fig 3 Annual number of deaths from scrotal cancer. 


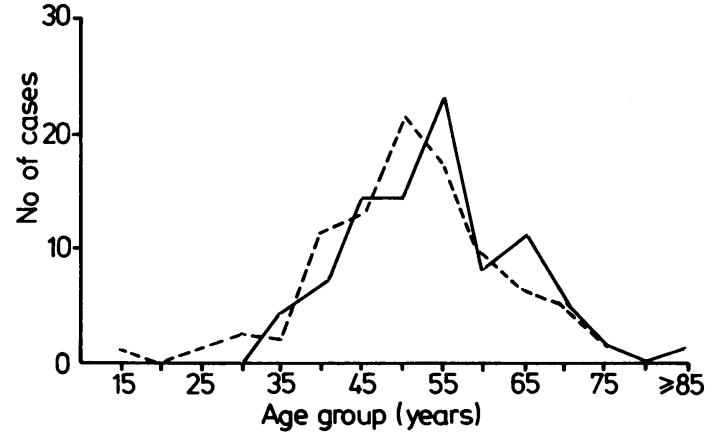

Fig 5 Age at onset (dashed line) and at registration (solid line) of 92 cases of scrotal cancer.

no history of exposure to any known carcinogens.

Figure 6 shows the proportion of cases (with known occupations) exposed to either pitch and tar or to mineral oil; the proportion of cases due to pitch and tar has declined continuously and the proportion with oil exposure has increased. It is notable that the age of registration of cases with exposure to oil, pitch and tar, or soot is significantly lower than in those in whom no occupational factors were discovered (table 2).

\section{LATENT PERIOD}

We were able to calculate the latent period between first exposure to oil and age at registration in 112 men; these data are shown in fig 7. There is necessarily an inverse relationship between age at registration and latent period, $r=-0.71(p<0.001)$, the mean latent period for the group as a whole being 34.4 years, standard deviation $12 \cdot 1$ years. We were also able to calculate the latent period in a group of nine men with exposure to pitch and tar. The mean for these men was $24 \cdot 3$ years.

Table 1 Principal occupations of men registered with scrotal cancer

\begin{tabular}{lrr}
\hline & No & \multicolumn{1}{l}{$\%$} \\
\hline Toolsetter, toolfitters & 89 & 25.9 \\
Machine operators & 49 & $14 \cdot 2$ \\
Metal workers & 19 & 5.5 \\
Cotton spinners & 6 & $1 \cdot 7$ \\
Labourers in oily jobs & 12 & 3.5 \\
Workers in other oily jobs & 38 & 11.0 \\
Workers with pitch and tar & 27 & 7.9 \\
Sweeps & 7 & $2 \cdot 0$ \\
Jobs with no relevant exposure & 57 & 16.6 \\
Exposure unknown & 12 & 3.5 \\
Occupation unknown & 28 & 8.1 \\
Total & 344 & 100.0 \\
\hline
\end{tabular}

A total of 213 occupations (61.9\%) involved exposure to mineral oil.

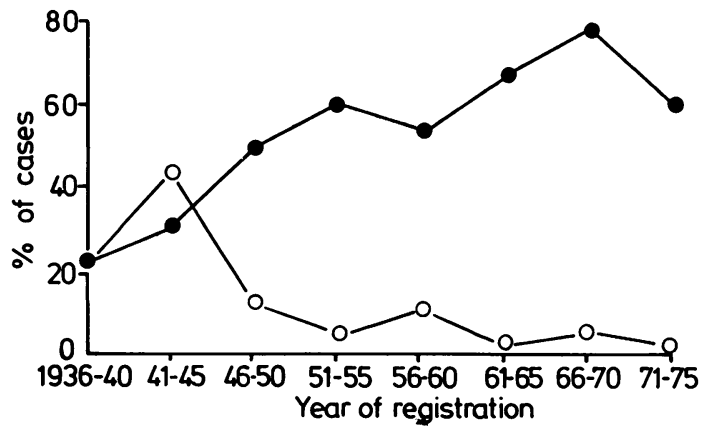

Fig 6 Proportion of cases of scrotal cancer due to exposure to mineral oil (closed circles) or to pitch and tar (open circles).

SURVIVAL

The mean survival after treatment of the 324 cases for whom it was known was 6.6 years (range 0 to 30 years). Figure 8 shows the percentage survival, calculated from a life table, from which it may be seen that the five year survival rate is $51 \%$. There has been no change in survival over time, the proportion of men surviving longer than five years between $1936-55,1956-65$, and $1966-76$ being $44.6 \%$, $44.2 \%$, and $44.6 \%$.

\section{TREATMENT}

Table 3 shows the forms of treatment given. Treatment of the disease has changed in recent years with an increasing proportion of patients being offered surgery without radiotherapy; the proportion of patients treated by radiotherapy alone has been small and constant over the years. The type of treatment offered does not vary with the age of the patient but patients with palpable lymph nodes are more likely to have been given radiotherapy as an adjunct to surgery than other patients (table 4).

\section{FACTORS AFFECTING SURVIVAL}

The factors which appear to affect survival include age at registration, the presence of palpable lymph nodes, and the type of treatment, the size of the presenting lesion per se does not significantly affect

Table 2 Age at registration related to type of exposure

\begin{tabular}{lllr}
\hline Exposure & Mean age (years) & \multicolumn{2}{l}{ Standard deviation No } \\
\hline Mineral oil & 56.7 & 10.7 & 213 \\
Pitch and tar or & 60.3 & 12.6 & 34 \\
$\quad$ soot & 64.2 & 12.5 & 57 \\
None & 66.4 & 10.2 & 37 \\
Not known & 59.3 & 11.7 & 341 \\
\hline
\end{tabular}

$F=14.1, p<0.001$. 


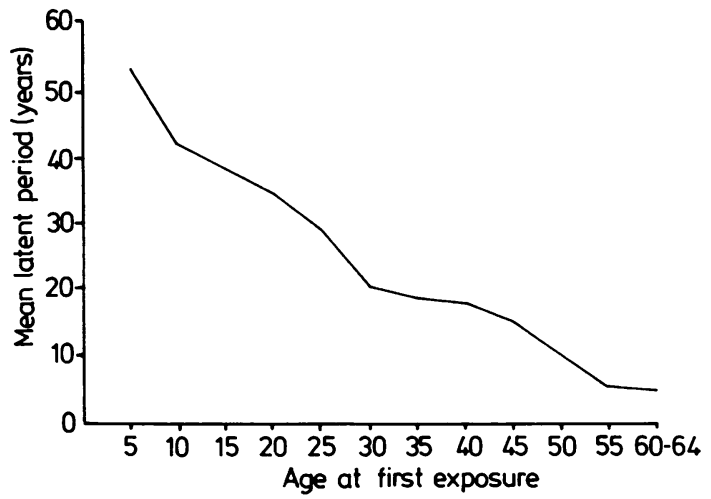

Fig 7 Latent period of scrotal cancer in relation to age at first exposure to mineral oil.

the duration of survival although, as may be seen from table 4 , the likelihood of node involvement increases significantly as the size of the lesion increases.

As might be expected, there is a significant negative correlation $(r=-0.39, p<0.001)$ between age at registration and duration of survival. The relation between the presence of lymph nodes and decreased survival holds good irrespective of the size of the lesion (table 5); the proportion of patients with lymph nodes surviving more than five years is only $26.4 \%$ compared with $61.3 \%$ in those whose lymph nodes are not affected $(p<0.001)$.

\section{SECOND PRIMARY TUMOURS}

In 74 cases second primary tumours were registered after the scrotal primary; 51 of these men had been exposed to mineral oil, five to pitch and tar, while in the remaining 18 there was no significant exposure. These differences were not statistically significant. The sites of the second primary tumours were the bronchus and the skin. Of the 51 second primary tumours in men exposed to mineral oil, 22 were in the bronchus and 12 in the skin; of the four second primaries in men exposed to pitch or tar, one was in the bronchus and three in the skin. Of the remaining 18 tumours, eight were in the bronchus and two in the skin.

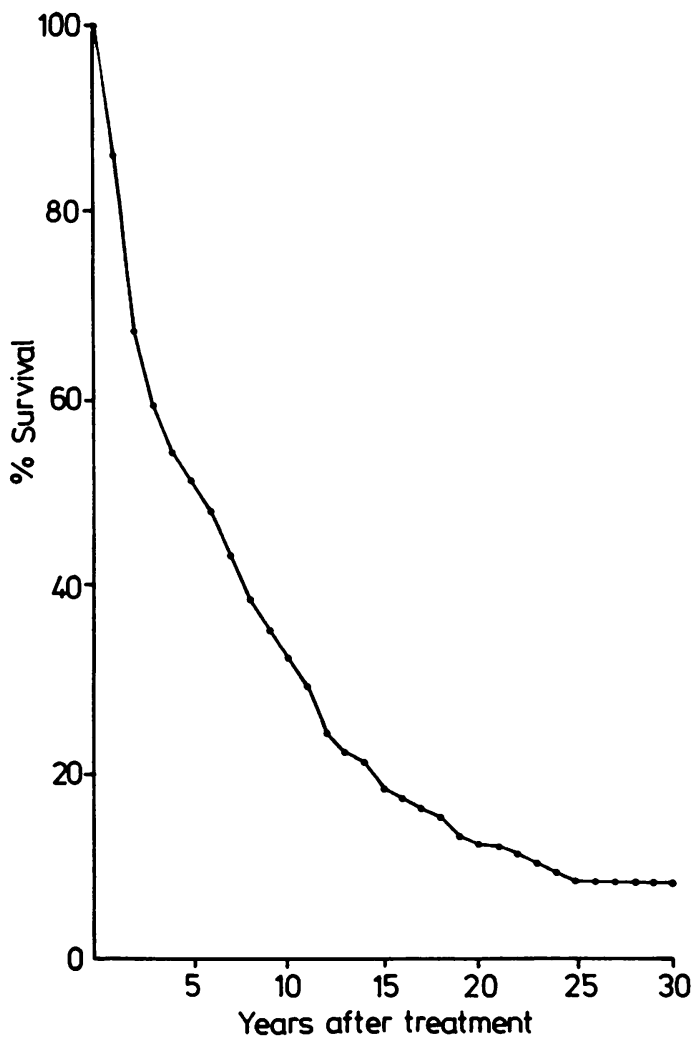

Fig 8 Percentage survival of cases with scrotal cancer.

\section{Discussion}

We have reported here on the largest series of cases of scrotal cancer since the publication of Henry's classic monograph in $1946.4^{4}$ The most striking feature of our series is the great increase in registrations during the 1950s after the report of Cruickshank and Squire. ${ }^{2}$ The carcinogenicity of cutting oils was confirmed in 1955 by Gilman and Vessolinovitch and cases of scrotal cancer due to exposure to cutting oils have been reported in many countries including America, ${ }^{6}$ Canada, $^{7}$ France $^{8}$ (especially in the valley of the Arve ${ }^{9}$, Norway, ${ }^{10}$ Sweden, ${ }^{11}$ and

Table 3 Type of treatment offered to patients with scrotal cancer

\begin{tabular}{|c|c|c|c|c|c|c|}
\hline & \multicolumn{2}{|c|}{ Surgery only } & \multicolumn{2}{|c|}{ Radiotherapy only } & \multicolumn{2}{|c|}{ Surgery and radiotherapy } \\
\hline & No & $\%$ & No & $\%$ & No & $\%$ \\
\hline $\begin{array}{l}1936- \\
1956- \\
1966-76 \\
\text { Total }\end{array}$ & $\begin{array}{r}37 \\
78 \\
87 \\
202\end{array}$ & $\begin{array}{l}54.4 \\
70.9 \\
80.6 \\
70.7\end{array}$ & $\begin{array}{r}5 \\
9 \\
9 \\
23\end{array}$ & $\begin{array}{l}7 \cdot 4 \\
8 \cdot 2 \\
8 \cdot 3 \\
8 \cdot 0\end{array}$ & $\begin{array}{l}26 \\
23 \\
12 \\
61\end{array}$ & $\begin{array}{l}38 \cdot 2 \\
20 \cdot 9 \\
11 \cdot 1 \\
21 \cdot 3\end{array}$ \\
\hline
\end{tabular}


Table 4 Choice of treatment offered to patients with scrotal cancer related to size of lesion and presence of palpable lymph nodes

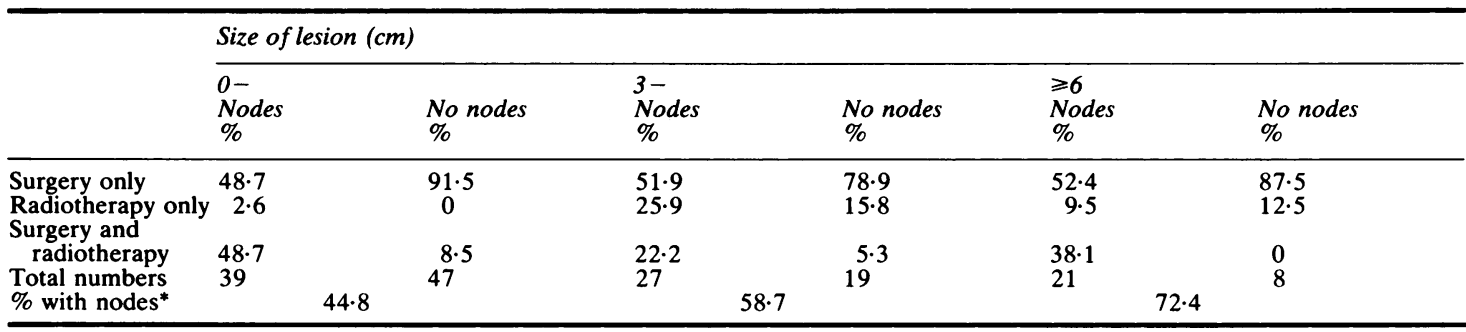

${ }^{*}$ Difference statistically significant at $5 \%$.

Australia. ${ }^{12}$ Even so, the disease was probably underreported until the Stokes $v$ GKN case; in the year after the case the number of cases of scrotal cancer reported to the factory inspectorate from the West Midlands Region (or Birmingham Region as it was known then) quadrupled from four in 1968 to 17 in $1969 .{ }^{13}$ (The increase in the number of cases registered in the region was 16 in 1968 and 21 in 1969 , suggesting some delay in notification.)

The number of cases registered in the region has remained high for two decades but now shows some indication of returning to the previous low level. This may well be due to the widespread introduction of solvent refined oils during the late 1960 s. If the decrease in the number of registrations continues then the rapidity of the response suggests a cocarcinogenic effect-that is, the mineral oil is acting as a promotional agent, perhaps as well as an initiator.

There is no doubt that the increase in the number of cases in the region was caused by exposure to mineral oil and, in all, three fifths of our cases had been employed in jobs which entailed some exposure to oil. Of the occupations within the group with oil exposure, the pre-eminent place is taken by tool setters and tool fitters who have supplanted mule spinners in this respect. There has been a steady

Table 5 Proportion of patients surviving more than five years related to size of lesion and presence of palpable lymph nodes

\begin{tabular}{|c|c|c|c|c|}
\hline & Size $(\mathrm{cm})$ & $\begin{array}{l}\text { \% Surviving more } \\
\text { than five years }\end{array}$ & No & $p$ \\
\hline $0-$ & $\begin{array}{l}\text { Nodes } \\
\text { No nodes }\end{array}$ & $\begin{array}{l}27 \cdot 0 \\
61 \cdot 7\end{array}$ & $\begin{array}{l}37 \\
47\end{array}$ & $<0.001$ \\
\hline \multirow{2}{*}{$\geqslant 6$} & $\begin{array}{l}\text { Nodes } \\
\text { No nodes }\end{array}$ & $\begin{array}{l}27 \cdot 6 \\
57 \cdot 1\end{array}$ & $\begin{array}{l}29 \\
21\end{array}$ & $<0.1$ \\
\hline & $\begin{array}{l}\text { Nodes } \\
\text { No nodes }\end{array}$ & $\begin{array}{l}23 \cdot 8 \\
75 \cdot 0\end{array}$ & $\begin{array}{r}21 \\
8\end{array}$ & $<0.05$ \\
\hline
\end{tabular}

increase in the proportion of cases which can be considered as due to oil exposure as shown in fig 6 . The decrease in cases arising from pitch and tar is also striking and is due in great part to the closure of a big tar distillery in the region.

What is perhaps equally striking from our data is the relatively high proportion of cases in which there was no obvious occupational factor. A total of 57 cases fell into this category $(16.7 \%)$, a much higher proportion than found by Lee and his colleagues ( 5 of $89,5 \cdot 6 \%)^{1}$ but similar to the proportion in Doig's series $(4$ of $21,19.0 \%) .^{14}$

A wide variety of occupations was represented among the group with no exposure to known carcinogens, the only occupations which included more than one case being labourers (7), woodworkers (3), pottery workers (3), gardeners (3), salesmen (2), butchers (2), school teachers (2), and blacksmiths (2). There were, in addition, two mentally subnormal patients who had never worked in their lives.

In some of these cases poor personal hygiene may have been a factor in the aetiology of the disease. The unclean state in which the patients presented was remarked on in half a dozen case notes; about one patient (a writer and journalist) the consultant wrote: "when he came in he was in a foul state, the skin of the scrotum was covered with sebum and it was literally a matter of forcing the man into the bath and holding him down so we could get him clean. We were very impressed with his total refusal and it does seem that he never ever bathed."

Table 6 Proportion of patients with scrotal cancer presenting with palpable lymph nodes

\begin{tabular}{llllll}
\hline & \multicolumn{2}{l}{ With nodes } & & \multicolumn{2}{l}{ Without nodes } \\
\cline { 2 - 3 } & No & $\%$ & & No & $\%$ \\
\hline $1936-$ & 44 & 77.2 & & 13 & 22.8 \\
$1956-$ & 63 & 65.6 & & 33 & 34.4 \\
$1966-76$ & 38 & 37.3 & & 68 & 62.7 \\
\hline$x^{2}=28.6, p<0.001$. & & &
\end{tabular}


The mean age at registration in our series was much lower than in the cases reported by Lee and his colleagues. ${ }^{1}$ They comment that "cancer of the scrotum is a disease of the elderly" and $41 \%$ of their cases were over 70 when they sought medical advice. By contrast, only $16 \%$ of our cases were over 70 when they registered. The difference in age between the two series is probably due in part at least to the fact that mule spinning has declined in the north west and hence fewer men are being exposed to oil. The cases now presenting in that region are thus likely to include a higher proportion of men who were exposed at a relatively late age or who have experienced a long latent period.

It is interesting to note that the men for whom there was an obvious occupational factor were significantly younger than the men whose tumour was apparently unconnected with their work; this is in agreement with the generally accepted observation that occupationally induced tumours occur at a younger age than those not related to work.

The mean age at death in our cases was 66 years which is similar to that found by Henry in his large survey. ${ }^{4}$ Henry reported that the mean age of death in his cases was 61.6 years while for mule spinners alone he found the mean to be 58.2 years. These figures again differ from the Manchester study in which $58 \%$ of the men were over 70 when they died. The reasons for this difference are clearly related to the fact that the disease has its onset at a later age in Manchester than in Birmingham for the reasons already mentioned.

It is generally accepted that solid tumours induced by chemicals or by ionising radiation require a long latent period. This term is variously described but is most often taken to be the time between first exposure to the carcinogen and clinical diagnosis. Our end point is given by the date of registration, which is seldom much later than the date of diagnosis. There are limitations to the use of date of diagnosis (or registration) as the end point of a latent interval, some of which have been discussed by Knox. ${ }^{15}$ One of the most obvious is that in some sites tumours will be more readily observed and diagnosed than in others. Skin tumours are likely to be diagnosed before intra-abdominal tumours, for example, so that the latent period may be longer in "hidden" tumours than in those on the surface. The latent period is also likely to be longer in tumours that produce few symptoms than in those that cause many.

The mean latent period in the men in our series exposed to mineral oil was 34.4 years (SD 12.1 years); Henry found a modal value of 35-39 years in mule spinners. ${ }^{4}$ Our mean value, however, conceals the negative correlation observed between latent period and age at first exposure (fig 7). This correlation may be obtained for other occupational tumours. For example, using the data given by Doll $^{16}$ for the induction of carcinoma of the bronchus in asbestos workers gives a correlation between latent period* and age at first exposure of $r=$ $-0.43, p<0.05$. The long latent period of 45.6 years for the induction of nasopharyngeal tumours in woodworkers (derived from the data of Acheson et $\left.a \mathbf{l}^{17}\right)$ is also associated with a negative correlation $(\mathrm{r}=-0.36)$ but this is not significant at the $5 \%$ level.

One explanation for the reduced latent period in the older age groups might be that tumours really are induced more quickly. It is much more likely, however, that the relationship is the consequence of the long induction time which does not allow for a sufficiently long duration of life in those first exposed to the carcinogen late in life. Only those in whom the latent interval is short will actually present with the disease and this will lead to an apparent, but spurious, negative correlation between latent period and age at first exposure.

About half the patients with scrotal cancer die within the first five years after diagnosis, a feature they have in common with patients suffering from a wide variety of malignant diseases: ${ }^{18}$ The factors which significantly affect survival include age at registration, treatment, and the presence of palpable lymph nodes. These factors are obviously interrelated since choice of treatment is affected by the clinical presentation of the patient, although not by his age. The number of patients treated by surgery alone has increased in recent years and this undoubtedly reflects the fact that the proportion of patients with palpable lymph nodes has decreased (table 6); there has been no change in the size of the presenting lesion with time. The effect on survival of age at registration is obvious; one does not expect that old men with the disease will live as long as younger men. Similarly, the presence of palpable lymph nodes indicates that the disease has spread beyond the confines of the scrotum and, as with other malignant disease, is more difficult to treat effectively. Having made allowance for age in a multiple regression equation, the presence of lymph nodes significantly shortens survival $(p<0.001)$ and, having allowed for both, surgery significantly prolongs survival $(p<0.001)$. The fact that survival was not related to the size of the lesion is perhaps unexpected given that node involvement is greater with increasing size. A postmortem study by Breuer and

*In this instance, latent period is taken as the interval between age at first exposure and death. It is unlikely, however, that in the case of bronchial carcinoma age at death is, on average, much greater than age at diagnosis. 
Ehring, however, has shown that large skin tumours have fewer distant metastases than those of medium size, indicating that the size of the presenting lesion may not always be a guide to the state of dissemination. ${ }^{19}$

The number of second primary tumours registered did not appear to differ significantly between the groups with known exposure to occupational carcinogens and those without, nor did the distribution of the sites of the second primaries significantly differ between the groups. This differs from our earlier observation ${ }^{20}$ that there was a significant excess of bronchial second primaries among the men with exposure to mineral oil.

This work was supported by a grant from the Institute of Petroleum which we acknowledge with gratitude. Some of the data were included in NTs MSc (Occupational Medicine) report presented to the University of London.

\section{References}

' Lee WR, Alderson MR, Downes JE. Scrotal cancer in the north-west of England, 1962-68. $\mathrm{Br} J$ Ind Med 1972;29:188-95.

${ }^{2}$ Cruickshank CND, Squire JR. Skin cancer in the engineering industry from the use of mineral oil. Br J Ind Med 1950; 7:111.

${ }^{3}$ Stokes $v$ GKN (Nuts \& Bolts) Ltd (1968), 1, Weekly Law Reports 1776.

${ }^{4}$ Henry SA. Cancer of the scrotum in relation to occupation. London: Oxford Medical Publications, 1946.
${ }^{5}$ Gilman JPW, Vesselinovitch SD. Cutting oils and squamous-cell carcinoma Part II: An experimental study of the carcinogenicity of two types of cutting oils. Br J Ind Med 1955;12:244-8.

${ }^{6}$ Kickham CJE, Dufresne M. An assessment of carcinoma of the scrotum. J Urol 1967;98:108-13.

${ }^{7}$ Mastromatteo E. Cutting oils and squamous-cell carcinoma Part 1: Incidence in a plant with a report of six cases. $\mathrm{Br} \mathrm{J}$ Ind Med $1955 ; 12: 240-3$.

${ }^{8}$ Carteaud A. Cancer du scrotum du au goudron ou a ses derives. La Presse Medicale 1964;72:3355-60.

${ }^{9}$ Kipling MD. Oil cancer in the Savoy Alps and the Birmingham region: a comparison. Transactions of the Society of Occupational Medicine 1971;21:73-8.

${ }^{10}$ Wannig A. Kreftrisiko og oljeeksposisjon. Tidsskrift for den Norske Laegeforening 1972;92:1136-40.

"Avellan L, Breine U, Jacobsson B, Johanson B. Carcinoma of scrotum induced by mineral-oil. Scand J Plast Reconstr Surg 1967; 1:135-40.

12 Kipling MD. Oil and cancer. Ann R Coll Surg 1974;55:71-9.

${ }^{13} \mathrm{HM}$ Chief Inspector of Factories. Annual Report 1969. London: HMSO, 1970.

${ }^{14}$ Doig AT. Epithelioma of the scrotum in Scotland in 1967. Health Bulletin 1970;28:45-51.

is Knox EG. Computer simulation of industrial hazards. $\mathrm{Br} \mathrm{J}$ Ind Med 1973;30:54-63.

${ }^{16}$ Doll R. Mortality from lung cancer in asbestos workers. Br J Ind Med 1955; 12:81-6.

17 Acheson ED, Cowdell RH, Rang E. Adenocarcinoma of the nasal cavity and sinuses in England and Wales. Br J Ind Med 1972;29:21-30.

${ }^{18}$ Waterhouse JAH. Cancer handbook of epidemiology and prognosis. London: Churchill Livingstone, 1974.

${ }^{19}$ Breuer I, Ehring F. Die Metastierung des Plattenepithelcarcinoms der Haut, an 11 ketamnesch und autopsien Untersucht. Archiv für Dermatologische Forschung (Berlin) 1972;245:277-84.

${ }^{20}$ Brown AJ, Waldron HA, Waterhouse JAH. Report on a study of occupational skin cancer. Birmingham: University of Birmingham, 1975. 